\title{
EL FRANCÈS COM A SEGONA LLENGUA ESTRANGERA AL CICLE SUPERIOR DE PRIMÀRIA
}

\author{
Sara Celma Gracià. Mestra del CEIP "Molí de Vent". Torredembarra
}

Cada cop més ens trobem més immersos en una societat multicultural i a la vegada plurilingüe, fet que ens aboca a una clara reflexió: aquesta no és ni més ni menys que la de fer-nos nous plantejaments en la nostra tasca d'educadors, i a la vegada de marcar-nos noves fites que proporcionin al nostre alumnat les eines necessàries per adaptar-se a aquesta societat tan rica i al mateix temps tan canviant i exigent.

La nostra escola, el CEIP Molí de Vent de Torredembarra, va aprofitar la possibilitat que el nou sistema educatiu ens oferia, és a dir, introduir una segona llengua estrangera al cicle superior de Primària, que en aquest cas fou la llengua francesa.

Aquesta iniciativa va sorgir principalment d'una proposta que l'AMPA Molí de Vent va fer al Consell Escolar del centre, la qual va ser estudiada i valorada favorablement pel claustre de professors. Una altra raó per tirar aquest projecte endavant era la similitud de la llengua francesa amb la nostra llengua, la qual cosa la feia més assequible als nostres alumnes. Al mateix temps, els IES de Torredembarra oferien al seu alumnat crèdits variables d'aquesta llengua, la qual cosa ens garantia la continuïtat de la nostra feina. Si, a més a més, el nostre poble és per naturalesa un poble amb forta afluència turística, això feia encara més rendible l'aprenentatge d'aquesta llengua.

Davant de totes aquestes raons, només ens quedava analitzar els recursos humans de què disposava la nostra escola per tirar-ho endavant. Veient que disposàvem de suficient professorat amb l'acreditació adequada, es va decidir acollir-nos a un programa d'innovació educativa, juntament amb altres escoles de les rodalies, que organitzava el Centre de Recursos de Llengües Estrangeres. En aquest programa hi vam participar dues professores del centre, que estàvem impartint classes al cicle superior i que disposàvem de la titulació necessària.

En aquest programa se'ns va facilitar material, orientació i preparació, ja que vam assistir a unes jornades "d'immersió lingüística" que es van dur a terme durant el mes de setembre a Barcelona. Es van realitzar diverses trobades, per fer una posada en comú de les experiències que les altres escoles havien dut a terme l'any anterior, ja que ja feia un any que s'havien acollit al programa.
A nivell organitzatiu de l'escola les classes de francès són impartides actualment per una professora.

L'alumnat de cicle superior està organitzat en tres grups classe d'uns vint-i-cinc alumnes aproximadament a cinquè i dos grups classe, també d'uns vint-i-cinc alumnes a sisè.

S'imparteix un hora setmanal a cada grup. Per fer aquesta hora s'ha disposat de mitja hora de llengua castellana i mitja de llengua catalana, que a la vegada són hores de lliure disposició.

L'espai on es fan les classes queda distribuït de la següent manera: sessions a l'aula ordinària, a l'aula de vídeo, al laboratori d'idiomes i a l'aula d'informàtica.

El material de què disposem és prou variat:

- Vídeos i cassettes que ens va proporcionar el Centre de Recursos de Llengües estrangeres.

- Material que hem anat confegint (jocs, cartrons de vocabulari, etc).

- Material comprat per l'escola com jocs manipulables, cassettes i CD's per treballar la llengua a l'aula d'informàtica, on gràcies a una suficient quantitat d'ordinadors podem treballar per parelles.

- No disposem de llibre de text, sinó d'una recopilació de fitxes fotocopiables i d'altres elaborades, agrupades per diferents unitats de programació $i$ graduades segons el nivell. Amb totes aquestes fitxes i d'altres d'ampliació i reforç l'alumne elabora un dossier que cal presentar a final de curs.

\section{La metodologia}

La metodologia es basa fonamentalment en la comprensió i l'expressió oral, és a dir, donant major importància a l'expressió i comprensió oral que no pas a l'escrita.

Per tant, en l'ensenyament de la segona llengua estrangera, el primer objectiu és que l'alumne domini els aspectes bàsics $i$ fonamentals de la llengua, en les dues vessants de comprensió i expressió oral, considerant que és molt important remarcar la prioritat que ha de tenir l'aspecte oral.

De cap de les maneres podem fonamentar l'aprenentatge d'una segona llengua estrangera en l'adquisició dels mecanismes de lectura i escriptura en aquesta 


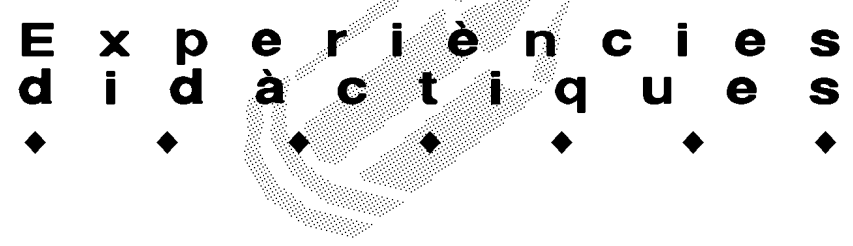

llengua, quan l'alumne no els té del tot assolits en la primera.

Per aconseguir aquest objectiu principal es disposa del material ja esmentat anteriorment, el qual hem procurat que tingui el rigor metodològic, una fàcil utilització i que al mateix temps sigui motivador a la vegada que ple de recursos, amb la finalitat que l'alumne augmenti la seva comprensió i pugui començar a parlar i a entendre la nova llengua.

La introducció d'aquest material és progressiva, a mesura que l'alumne disposa d'uns recursos lingüístics mínims per poder-ne fer un ús més profitós.

El primer trimestre es destina principalment a una presa de contacte amb la nova llengua. L'espai físic on es desenvoluparan les classes serà l'aula. No serà fins al segon trimestre que s'introduirà el vídeo: Le petit monde de Pierre, com a material nou i motivador de treball. Aquests vídeos consten de vuit capítols que van directament relacionats amb les unitats de programació treballades a l'aula amb fitxes; quatre capítols es treballaran a cinquè i els altres quatre a sisè. A tall d'exemple, si a l'aula es treballa la unitat de programació Les habillements, a l'aula de vídeo veurem el capítol Les habits du roion els personatges desenvolupen una historieta relacionada amb la roba de vestir.

Les cassettes són material de suport molt important, ja que ens ajuden a realitzar algunes de les fitxes proposades i a la vegada ens permeten sentir parlar la llengua a persones del país.

No és fins a sisè que utilitzem l'aula d'ordinadors, ja que aquestes activitats exigeixen que la comprensió oral sigui suficient $\mathrm{i}$ al mateix temps uns mínims de comprensió escrita per poder-les realitzar; de totes formes l'experiència ens ensenya que no és del tot imprescindible, ja que compten amb l'ajut del professor i, evidentment, de la seva lògica que en aquest món de la informàtica, siguem realistes, els nostres alumnes en tenen la mà trencada.

Tant les activitats als ordinadors com al vídeo i el treball d'algun conte o cançó resulten del tot engrescadores i enriquidores. Per poder dur a terme aquestes activitats és necessari disposar d'unes pautes de treball que ens permetin treure'n el màxim profit. Us proposem un exemple de com treballar bé sigui un conte o un capítol d'un vídeo. No cal dir que cada mestre/a en farà la seva pròpia adaptació.

\section{Conte/vídeo}

\section{Primera audició}

El professor llegeix el text i els nens llegeixen el dibuix, és a dir, han d'associar allò que s'entén amb les imatges que tenen al davant.
El professor llegirà d'una manera seguida, sense interrupcions i a una velocitat normal, encara que alguns nens, o tota la classe, no ho segueixin prou bé.

És important marcar bé l'entonació i les pauses i ferhi la mímica adient.

En el cas d'un capítol de vídeo, es farà també un primer visionament sense interrupcions.

\section{Explicació}

Un cop feta la primera lectura del conte o la primera projecció del vídeo, tornarem a començar l'historia des del començament. Aquesta vegada hem d'aturar-nos sempre que calgui aclarir una paraula i aprofundir en una altra si convé.

Les paraules i expressions del text o audició que són de difícil comprensió probablement s'hauran d'explicar algunes vegades; amb d'altres, però, no caldrà fer-ho. Així polsarem el nivell de comprensió de la classe per no deixar llacunes en la comprensió.

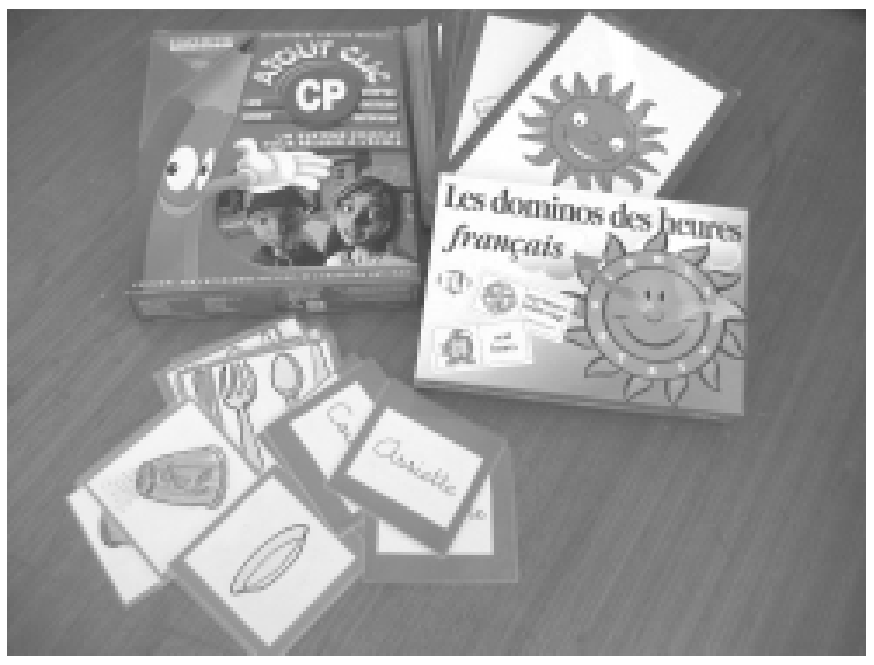

Cal que aquesta explicació sigui com més activa millor i si no és possible, haurem de recórrer a la mímica i al dibuix, a la perífrasi, al sinònim etc.; a tot menys a la traducció. És important no traduir mai, de la mateixa manera que és important parlar ja des del començament i sense concessions, en francès.

En aquesta fase d'explicació l'alumne molt probablement no lligarà els elements que va comprenent ni els situarà dintre d'un context unitari i, possiblement, en acabar la fase no haurà entès globalment el conte 0 vídeo, però sí els elements separats que el componen, i per tant estarà preparat per comprendre'l a la fase següent.

\section{Nova audició}

Cal tornar a llegir el text i/o escoltar el capítol del vídeo, d'una manera seguida, sense interrupcions. És ara quan la comprensió de la història va assolint-se (si 


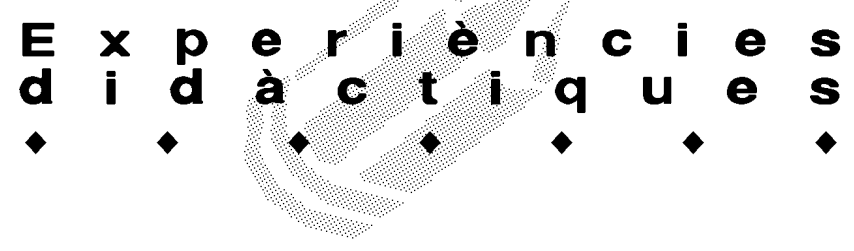

l'explicació ha estat efectiva en la fase anterior).

\section{Repetició}

Després d'haver sentit/vist aquestes tres vegades el conte/vídeo els nens el repetiran, frase per frase: el mestre en llegeix o repeteix una, i dos o tres alumnes la repetiran i de la mateixa manera ho faran tots els alumnes de la classe. No és necessari que cada alumne repeteixi totes les frases del conte/vídeo. Aquesta etapa mecànica de la repetició és molt important dins el procés d'adquisició d'una segona llengua.

\section{Preguntes de comprensió}

Les preguntes de comprensió que fem sobre el fragment del text explicat o seqüència vista són tancades, és a dir, tenen una sola possibilitat de resposta i, encara, aquesta resposta ha de ser un fragment literal del conte o del diàleg del vídeo, sense transformacions pronominals ni canvis verbals. Si no ho fem així, el nen no tindrà elements per fer una resposta correcta, es pot inhibir o bé respondrà en català 0 castellà (no seria negatiu, ja que demostra que ha entès la pregunta), però podria crear alguns hàbits erronis que després costaria desarrelar.

\section{Representació}

Com que la línia dels arguments dels contes que triarem serà molt simple, es pot arribar a fer la representació d'alguna de les seqüències, després d'haver-ho memoritzat.

\section{Objectius didàctics}

- Percebre l'entonació i el ritme de la llengua francesa.

- Representar mínimament les accions més comunes presentades en el conte/vídeo.

- Comprendre i identificar el lèxic treballat a la unitat.

- Reproduir un diàleg pautat relacionat amb una situació d'una seqüència determinada del conte/ vídeo.

- Utilitzar el vocabulari i estructures de la unitat de forma contextualitzada.

- Saber explicar una seqüència determinada del conte/vídeo.

- Preguntar i respondre sobre qüestions relacionades amb el conte/vídeo.

- Participar en la representació del conte o escena de vídeo.

- Utilitzar correctament el lèxic après.

- Comprendre les instruccions donades pel mestre/ a a fi de realitzar les activitats d'aprenentatge.

- Interpretar i descriure el que representa una làmina/escena.

- Aprendre frases fetes per poder aplicar-les i utilitzar-les.
- Participar activament en les activitats d'aprenentatge.

- Respectar el torn de paraula i les intervencions dels companys/es.

\section{Continguts}

Procediments

- Visionament del conte/vídeo.

- Visionament i comprensió global del conte.

- Visionament i comprensió analítica.

- Memorització del vocabulari i camps semàntics

- Presentacions i descripcions curtes i orals (de persones, de coses i de l'entorn).

- Ubicació en l'espai mitjançant la pregunta: "Oú...?" i les respostes: sur - sous - dans...

- Comparació mitjançant "comme": petit - grand joli - longue - court.

- Ús de recursos no lingüístics com a suport de l'expressió.

Fets i conceptes

- Funcions comunicatives (com poden ser: salutació, presentació, acomiadament, etc.).

- Expressió de la causa: Pourquoi... ? Parce que...

- Comprensió i expressió de les accions relacionades i utilitzades en l'escena del conte o en el capítol del vídeo.

- Elements de morfosintaxi.

- La negació i l'afirmació.

- Adjectius com: longue - court - gran - petite - joli (relacionats amb el tema).

- Colors: vert - rouge - marron - jaune - bleu blanche.

- Locatius: oú? - sur - sous - dans.

- Interrogatius (que sorgeixin): quel - quelle - qui...

Actituds

- Mostrar curiositat per conèixer la nova llengua.

- Esforçar-se a fer correctament les produccions orals.

- Participar activament en les activitats proposades.

\section{L'avaluació}

L'avaluació es farà oral, de forma continuada i valorant sempre la comprensió i l'expressió oral de l'alumne, al mateix temps que el seu esforç i interès per assolir les estructures i el vocabulari treballat. Cada mestre/a triarà les activitats i preguntes més adients per tal de poder dur a terme aquesta avaluació. 